This item was submitted to Loughborough's Research Repository by the author.

Items in Figshare are protected by copyright, with all rights reserved, unless otherwise indicated.

\title{
Characterisation and humidity-sensing properties of aluminium (oxy)- hydroxide films prepared by cathodically induced precipitation
}

PLEASE CITE THE PUBLISHED VERSION

http://dx.doi.org/10.1016/j.snb.2007.05.040

PUBLISHER

(C) Elsevier B.V.

VERSION

AM (Accepted Manuscript)

LICENCE

CC BY-NC-ND 4.0

\section{REPOSITORY RECORD}

Mortimer, Roger J., and Russell J. Mayes. 2019. "Characterisation and Humidity-sensing Properties of Aluminium (oxy)-hydroxide Films Prepared by Cathodically Induced Precipitation”. figshare.

https://hdl.handle.net/2134/11425. 
This item was submitted to Loughborough's Institutional Repository (https://dspace.lboro.ac.uk/) by the author and is made available under the following Creative Commons Licence conditions.

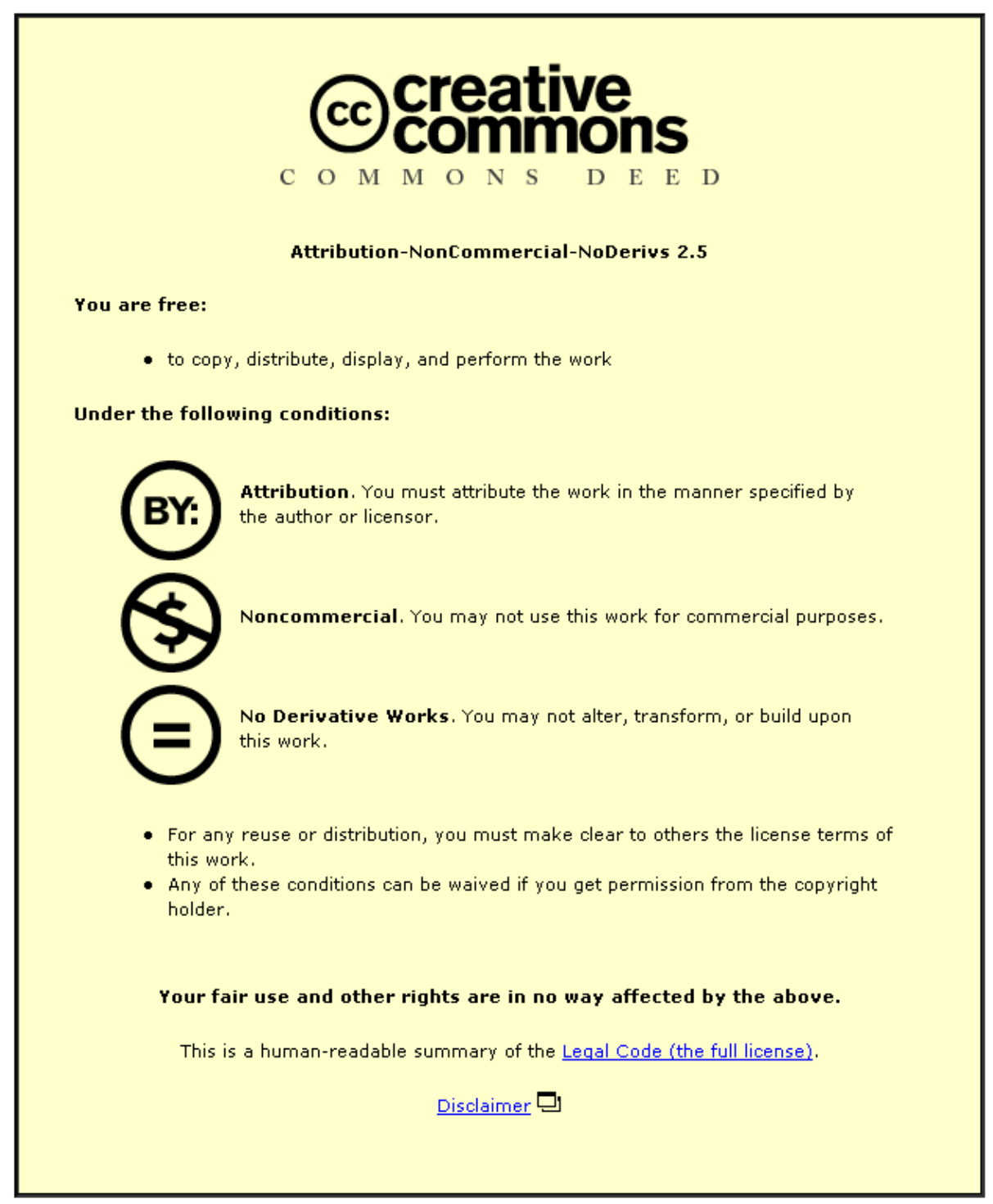

For the full text of this licence, please go to: http://creativecommons.org/licenses/by-nc-nd/2.5/ 


\title{
Characterisation and humidity-sensing
}

\author{
properties of aluminium (oxy)-hydroxide films
}

prepared by cathodically-induced precipitation

\author{
Roger J. Mortimer*, Russell J. Mayes \\ Department of Chemistry, Loughborough University, Loughborough, Leicestershire, LE11 3TU, UK
}

${ }^{*}$ Corresponding author. Tel.: +44 (0) 1509 222583; fax: +44 (0) 1509223925.

E-mail address: R.J.Mortimer@lboro.ac.uk (R.J. Mortimer). 


\begin{abstract}
Cathodically-induced precipitated aluminium (oxy)-hydroxide films, prepared using hydrogen-sorbing palladium electrodes, have been characterised and their humidity-sensing electrical properties studied. Infrared (IR) spectroscopy demonstrated that the films are hygroscopic, and this property allows their use as the active component in a humidity sensor. Films formed as bridging precipitates between twin palladium electrodes were tested for electrical parameter response to relative humidity changes. A linear correlation with impedance is obtained on application of a $100 \mathrm{mV}$ applied ac signal amplitude at $1 \mathrm{kHz}$. The linearity of response is comparable to commercial sensors. Cathodically-induced precipitate films contain $24 \mathrm{wt} \%$ aluminium and $10 \mathrm{wt} \%$ sulfate, the balance being oxygen and hydrogen. As-deposited films are amorphous, but change to a crystalline form after heat treatment at high temperature. XRD patterns taken as films are heated reveal transformation into $\gamma$ $\mathrm{Al}_{2} \mathrm{O}_{3}$, followed by production of $\alpha-\mathrm{Al}_{2} \mathrm{O}_{3}$ at temperatures greater than $1100^{\circ} \mathrm{C}$. An electrochemical quartz crystal nanobalance (EQCN) study demonstrated that dissolution of the precipitate is possible at positive potentials, cycling to which allows film compaction.
\end{abstract}

Keywords: Humidity sensor; Aluminium (oxy)-hydroxide; Electrochemical; Sensing properties 


\section{Introduction}

Electrochemical generation of base from aqueous metal salt solutions is a simple and inexpensive route to the synthesis of ceramic oxide thin films and powders [1]. Choice of electrolyte composition and electrochemical reduction regime provides a number of different base-generation mechanisms, including reactions that consume $\mathrm{H}^{+}$ions, anion reduction reactions, and the electrolysis of water. All these reduction reactions cause a pH increase at the electrode/electrolyte interface, and, depending on the metal deposition potential, may compete with the metal ion reduction reaction. Previous applications of cathodic precipitation include the preparation of precursors to pre-shaped ceramic bodies [2], superconducting oxides [3-6], and electrochromic films [7-11].

We are interested in generating films with gas sensing properties, using a technique that involves the electrolysis of aqueous non-dischargeable metal salt solutions, such as aluminium sulfate. Electrochemical generation of hydrogen at the cathode surface results in local generation of hydroxide ions. Such conditions promote the precipitation of metal oxyhydroxides ${ }^{\dagger}$, and if the local alkaline environment is not disrupted by convection, then a solid phase accumulates at the cathode, and forms an adherent surface film. In order to maintain deposition, it is essential that gaseous hydrogen evolution is eliminated and this is achieved by use of a hydrogen-sorbing cathode substrate, such as palladium [2]. Both porous and compact ceramic precursor structures can be generated, depending on the electrode potential programme employed during deposition [12]. We have earlier reported the preliminary evaluation of cathodically-induced precipitation to the manufacture of humidity sensing materials

\footnotetext{
'The term 'oxyhydroxide' is often used to describe the insoluble oxide/hydroxide mixtures of indeterminate ratio. In the work reported here, we use the term (oxy)-hydroxide to highlight the dominant species as hydroxide.
} 
[13]. It was reasoned that the electrochemical generation of ceramic precursors would be ideally suited to the fabrication of such devices, since their sensing performance is linked to the substrate porosity. A high degree of porosity is required in order to provide the necessary hygroscopicity to facilitate access of water vapour from the sensed atmosphere to the sensing material. Aluminium (oxy)-hydroxide is our material of choice for film formation, since alumina-based humidity sensors are widely used and are well-characterised devices [14].

In our earlier work [13], linear impedance responses were obtained in each of the ranges $6-40$ and $40-90 \%$ relative humidity. AC impedance analysis was employed to probe the electrochemically generated sensing film's conduction mechanisms at various humidity levels, and an equivalent circuit model, based on two parallel RC circuits, has been proposed [13]. We now describe a detailed study of the cathodically-induced precipitation of aluminium (oxy)-hydroxide films and their characterisation using X-ray diffraction (XRD), scanning electron microscopy (SEM), and infrared (IR) spectroscopy. To explore the response of various electrical parameters to humidity changes, aluminium (oxy)-hydroxide films were prepared as bridging precipitates across twin palladium working electrodes. Performance characteristics were compared with commercial humidity sensors.

\section{Experimental}

\subsection{Electrochemical procedures and the twin electrode design}

A standard electrochemical workstation, with appropriate software, was used for all electrochemical experiments. For preparation of bulk material for characterisation, a multi-channel galvanostat was designed and constructed, which could simultaneously produce a current of up to $\pm 30 \mathrm{~mA}$ across 5 channels. A threeelectrode cell setup was used for potentiostatic and potentiodynamic experiments, the 
cell design incorporating a Luggin capillary and Bioanalytical Systems RE-5B $\mathrm{Ag} \mid \mathrm{AgCl}\left(3 \mathrm{~mol} \mathrm{dm}^{-3} \mathrm{NaCl}\right)$ reference electrode $(+0.213 \mathrm{~V}$ versus SHE) in a separate compartment. All potentials reported here are versus the $\mathrm{Ag} \mid \mathrm{AgCl}\left(3 \mathrm{~mol} \mathrm{dm}{ }^{-3} \mathrm{NaCl}\right)$ half cell. A platinum gauze counter electrode was used. Two-electrode circuitry was used for galvanostatic experiments, the working and counter electrodes being parallel to each other. All current densities refer to the geometric surface area of the electrode.

The twin electrode design was modified from the original design [13], with spacer film (50 $\mu \mathrm{m}$, Mylar ${ }^{\circledR}$ ) now being included between the two sheets of palladium. In order to eliminate stress, the palladium was not folded, twin electrodes being fabricated by cutting two rectangular pieces of palladium sheet, $0.5 \mathrm{~cm}$ by $1 \mathrm{~cm}$. Two copper wire contacts were soldered onto the ends of the palladium sheet. Mylar film, slightly larger than the pieces of palladium sheet, was cut and superglued between the two pieces of the palladium. The whole assembly was then set in Araldite ${ }^{\circledR}$ (24 h hardening, Bostik $\left.{ }^{\circledR}\right)$ at the end of a glass tube (11 mm outer diameter). Twin palladium strips were exposed by grinding through the Araldite ${ }^{\circledR}$, with a Buehler electrode grinder/polisher with abrasive paper (Buehler, Carbimet P1200). Before use, the electrodes were polished with increasingly fine alumina suspensions, finishing with $0.3 \mu \mathrm{m}$ alumina polishing powder.

\subsection{Thin-layer cell for $p H$ change measurements}

A cell was fabricated from two microscope slides, $76 \mathrm{~mm}$ by $50 \mathrm{~mm}$, which were mounted $1.5 \mathrm{~mm}$ apart. Araldite ${ }^{\circledR}$ secured the two slides together around three sides and prevented the solution from leaking. The cell was clamped and the test solution containing universal indicator (Aldrich) was added. The working electrode and counter electrode were palladium and platinum wire respectively, and these were 
mounted at either end of the cell. A constant reduction current of $-2 \mathrm{~mA}$ was applied to the cell.

\subsection{Aluminium (oxy)-hydroxide film deposition}

Solutions for film preparation were prepared by dissolution of aluminium (III) sulfate (Aldrich, 99.99\% anhydrous) to $0.01 \mathrm{~mol} \mathrm{dm}^{-3}$ in Milli- ${ }^{\circledR}$ deionised water (18.2 $\mathrm{M} \Omega \mathrm{cm})$. No supporting electrolyte was used, because all supporting electrolytes tested either co-precipitated or prevented precipitate formation completely. The films prepared for characterisation were generated using palladium flag electrodes, with an applied reduction current density of $-20 \mathrm{~mA} \mathrm{~cm}{ }^{-2}$ for $40 \mathrm{~min}$. Precipitates were dried in air to produce films and then removed and collected to generate enough material for analysis.

The twin electrode setup was used to test the films' response to relative humidity. A successful film was precipitated, if a 'bridge' was formed by the film between the two electrodes. This allowed the film to be tested by applying an ac waveform between the two electrodes. For deposition, the two palladium electrodes were short circuited and used as the working electrode. For galvanostatic experiments the counter electrode was placed in parallel to the working electrode. Successful bridging between the two electrodes occurred, when a galvanostatic current density of $-20 \mathrm{~mA} \mathrm{~cm}{ }^{-2}$ was applied for $45 \mathrm{~min}$. Other techniques which generated a successful bridged precipitate were a potential of $-3.2 \mathrm{~V}$ versus $\mathrm{Ag} \mid \mathrm{AgCl}\left(3 \mathrm{~mol} \mathrm{dm}{ }^{-3} \mathrm{NaCl}\right)$ applied for $45 \mathrm{~min}$, and when the potential was stepped between $-3.2 \mathrm{~V}$ and $0.5 \mathrm{~V}$ at $20 \mathrm{~s}, 30 \mathrm{~s}$ or $40 \mathrm{~s}$ intervals for $1 \mathrm{~h}$.

\subsection{Material characterisation techniques}

A Leo 1530 Field Emission Gun Scanning Electron Microscope system was used for scanning electron microscopy (SEM), with an EDAX ${ }^{\circledR}$ detector attached for 
EDX analysis. Samples for analysis were mounted on SEM stubs using double sided carbon tape, before being coated with a thin layer of gold.

The XRD instrument used was a Bruker D8 advance diffractometer, with Xrays of wavelength $1.5406 \AA$ from a copper source. Room temperature XRD patterns were obtained with $2 \theta$ values between $15^{\circ}$ and $70^{\circ}$. Thermal ramp experiments were also carried out using an Anton Parr HTK 1200 heated sample stage, which allowed precise control of the temperature. XRD patterns were recorded at 800, 900, 1000, 1100 and $1150^{\circ} \mathrm{C}$. Samples were allowed to cool to $200^{\circ} \mathrm{C}$ for a further XRD pattern. Samples were mounted on a silicon wafer (100, Aldrich), which removed reflections from the pattern due to the furnace sample holder, which itself was made from aluminium oxide. Data collection took place over 60 min between $15^{\circ}-70^{\circ} 2 \theta$ using a $0.0147^{\circ} 2 \theta$ step. All data collected were compared against patterns stored in the Joint Committee on Powder Diffraction Standards database.

Standard IR analysis was undertaken using a Shimadzu FTIR 8300 spectrometer and then spectra were recorded between $400-4000 \mathrm{~cm}^{-1}$. For XPS analysis a VG Scientific ESCALAB instrument was used. For inductively coupled plasma mass spectrometry (ICP-MS) analysis a ThermoElemental PQ ExCell instrument was used.

For electrochemical quartz crystal nanobalance (EQCN) studies, AT-cut bonded and unpolished gold coated quartz crystals were obtained from Elchema. They had a resonant frequency of $10 \mathrm{MHz}$ and had a layer of chromium between the quartz and the gold to aid adhesion. The EQCN used was an Elchema EQCN-700, attached to an AdInstruments PowerLab 8SP analogue to digital converter. A layer of bright palladium was electro-deposited onto the surface of the gold coated quartz crystals, using an aqueous solution of palladium chloride $\left(0.01 \mathrm{~mol} \mathrm{dm}^{-3}\right)$ and potassium 
hydroxide $\left(0.7 \mathrm{~mol} \mathrm{dm}{ }^{-3}\right)$. A constant reduction current of $-1.614 \mathrm{~mA}$ was applied to the quartz crystal working electrode, until approximately $16 \mu \mathrm{g}$ of palladium had been deposited.

\subsection{Controlled humidity environments}

Constant humidity chambers were made from glass, $22 \mathrm{~cm}$ in height and $8 \mathrm{~cm}$ in diameter, with each saturated salt solution filling the bottom $1 \mathrm{~cm}$ of each chamber. Salts used and the relative humidity retained above them are outlined in Table 1. Each salt was recrystallised from boiling deionised water. Two ground glass joints were situated at the top of each chamber to facilitate access for the electrode being tested, reference humidity sensor or thermocouple. The accuracy of the saturated salt solutions was checked by a Vaisala HMP45 humidity and temperature probe attached to a HMI41 indicator unit. The Vaisala probe was calibrated against factory working standards, which have an accountable trail back to a primary standard in use by the National Institute of Standards and Technology. The probe was within tolerance for all saturated humidity solutions at $25^{\circ} \mathrm{C}$. The humidity chambers were maintained at $25^{\circ} \mathrm{C}$ using a Julabo oil bath, with feedback thermocouple.

\subsection{Electrical parameter response measurement to relative humidity}

The electrical response of aluminium (oxy)-hydroxide films formed as bridged precipitates across a twin palladium electrode to various relative humidities was monitored using a Wayne Kerr precision component analyser, model 6425. Each film was exposed to a particular relative humidity and then readings were recorded after 2 h. In order to ensure reproducibility, films were then removed and exposed to ambient air for at least $1 \mathrm{~h}$ before exposure to the next relative humidity. This was repeated 4 times for each film to ensure reproducibility. The applied ac voltages were $20 \mathrm{mV}$, $100 \mathrm{mV}, 200 \mathrm{mV}, 500 \mathrm{mV}$ and $1 \mathrm{~V}$. The 40 frequencies used were between $20 \mathrm{~Hz}$ to 
$300 \mathrm{kHz}$. For each applied ac voltage and frequency the impedance, resistance, capacitance and inductance of the film were recorded at 11, 29, 33, 43, 51, 65, 75 and $85 \%$ relative humidity.

\section{Results and discussion}

3.1. Preparation and characterisation of aluminium (oxy)-hydroxide films from cathodically-induced precipitation

Electrolysis experiments, using a palladium cathode and a platinum anode in a thin-layer electrochemical cell containing universal indicator solution, illustrated the $\mathrm{pH}$ changes that occurred at the electrode surface and allowed confirmation of the cathodically-induced precipitation mechanism. A constant reduction current of $-2 \mathrm{~mA}$ was first applied to the cell containing just aqueous universal indicator solution. After $15 \mathrm{~s}$ a thin dark purple ( $\mathrm{pH}$ 10) layer, indicating generation of hydroxide ions, was visible near the palladium surface and continued to extend out into solution for as long as the current was applied. Between the slightly acidic bulk and the basic electrode a region of graduated $\mathrm{pH}$ was observed, with colours between red $(\mathrm{pH} 4)$ and dark purple (pH 10) visible. At the surface of the platinum counter electrode the universal indicator remained red. When aluminium sulfate $\left(0.01 \mathrm{~mol} \mathrm{dm}^{-3}\right)$ was added to a fresh universal indicator solution and the electrolysis repeated, no $\mathrm{pH}$ change near the surface of the palladium cathode was observed. When the palladium electrode was removed, a precipitate covered the surface, as likewise found when the experiment was repeated in the absence of universal indicator. This simple experiment proved that the hydroxide ions produced at the electrode surface were involved in the formation of the precipitate.

Preliminary experiments were carried out to establish an electrode preparation regime for the reproducible production of adherent aluminium (oxy)-hydroxide films 
that showed good structural integrity. Pre-treatment of palladium in $1 \mathrm{~mol} \mathrm{dm}{ }^{-3}$ sulfuric acid (>30 min), acetone and ceric sulfate solution (>24 h) to remove residue, organics and hydrogen respectively, was found to allow indefinite reuse of palladium for repeated hydrogen sorption and film deposition. Although palladium prepared by this method aged, with cracks and crinkles appearing, this had no detrimental effect on the ability of the palladium to sorb hydrogen and to allow cathodically-induced precipitation. Oxidation of sorbed hydrogen using the ceric sulfate solution was essential, with neither electrochemical 'outgassing' in either aluminium sulfate (0.01 mol $\left.\mathrm{dm}^{-3}\right)$ or sulphuric acid $\left(1 \mathrm{~mol} \mathrm{dm}{ }^{-3}\right)$, nor flaming allowing sufficient removal of hydrogen for continuous reuse of palladium electrodes for cathodically-induced precipitation.

Electrodes fabricated from palladium wire were initially used for investigation of the appropriate electrochemical potential/current regime for successful cathodically-induced film formation from $0.01 \mathrm{~mol} \mathrm{dm}^{-3}$ aluminium sulfate solution. Potentiostatic deposition provided a simple method for precipitate formation but it took a relatively long time to form a stable deposit. For practical precipitate formation (observation of a precipitate within $30 \mathrm{~min}$ ) a potential of at least $-1.3 \mathrm{~V}$ versus $\mathrm{Ag} \mid \mathrm{AgCl}$ (3 $\left.\mathrm{mol} \mathrm{dm}^{-3} \mathrm{NaCl}\right)$ had to be applied to the cell. However precipitates formed at these potentials were very loose and were easily removed from the electrode surface. A potential of $-3.2 \mathrm{~V}$ versus $\mathrm{Ag} \mid \mathrm{AgCl}\left(3 \mathrm{~mol} \mathrm{dm}{ }^{-3} \mathrm{NaCl}\right)$ was found to produce the best potentiostatically formed precipitates, with the time taken to form these deposits successfully varying from 60 to $80 \mathrm{~min}$. For galvanostatic deposition, a series of constant reductive current densities from -5 to $-30 \mathrm{~mA} \mathrm{~cm}{ }^{-2}$ were investigated, with the most successful precipitates being produced at $-20 \mathrm{~mA} \mathrm{~cm}$. Precipitates formed at lower current densities were less adherent than those formed at 
higher current densities. At current densities greater than $-25 \mathrm{~mA} \mathrm{~cm}{ }^{-2}$, the precipitate was loose rather than compact. Successful precipitate formation for the $-20 \mathrm{~mA} \mathrm{~cm}{ }^{-2}$ experiments occurred between 30 and 50 min. After this time hydrogen gas bubbles, attributed to a saturated palladium electrode, were observed on the electrode surface, which destroyed the structural integrity of the deposit. For cyclic voltammetry, disc electrodes were used to minimise solution potential drop. Cyclic potential deposition, between 0.5 and $-3.2 \mathrm{~V}$ versus $\mathrm{Ag} \mid \mathrm{AgCl}\left(3 \mathrm{~mol} \mathrm{dm}^{-3} \mathrm{NaCl}\right)$, produced structurally sound precipitates when the scan rate was between 50 and $100 \mathrm{mV} \mathrm{s}^{-1}$. At lower scan rates the precipitate formed, but did not adhere to the electrode and was not compact.

SEM data provided pictures of the samples as well as compositional information, through use of an EDX instrument, data confirming the presence of aluminium, oxygen and sulfur (most likely as residual sulfate) as elements present on a sample of the aluminium (oxy)-hydroxide. SEM images and EDX data were independent of electrochemical deposition technique, samples showing a range of particles of varying sizes up to $100 \mu \mathrm{m}$. On further magnification, a porous structure is observed (Fig. 1), which would allow fresh solution to diffuse to the electrode surface during precipitate formation, and, when used as a gas sensor, the benefit of gas diffusion to a large surface area. IR spectra (Fig. 2) indicated metal hydroxide bonds and confirmed the presence of residual sulfate in the aluminium (oxy)hydroxide film. Samples were hygroscopic, and even if placed in a vacuum overnight before disc pressing, IR spectra still indicated the presence of bands attributed to water. The rapidity at which films absorbed water is encouraging for humidity sensing applications. Gravimetric analysis, with barium sulfate precipitation, established a $10.1 \pm 2.5$ wt\% bulk film sulfate content. This result was consistent with XPS analysis, showing that the surface sulfate content was not enhanced by aluminium 
sulfate deposition. Aluminium content (23 wt\%) by XPS was similar to that ( $24 \mathrm{wt} \%$ ) determined by ICP-MS.

The electrochemical quartz crystal nanobalance (EQCN) was used to investigate the mass change associated with precipitate deposition on the palladium electrode. The formation of precipitate with appropriate structural integrity was sufficient to cause the quartz crystal to stop vibrating, so the preparation of a very thin film (as confirmed by SEM) from a single voltammetric cycle with the waveform as indicated in Fig. 3 was investigated. Mass changes from EQCN data (Fig. 3) showed that the electrode deposit formed from approximately $-0.6 \mathrm{~V}$. The deposit mass then increases rapidly up to $10 \mu \mathrm{g}$ at $-1.0 \mathrm{~V}$ on the reverse cycle. The cathodically-induced precipitation process can be explained by the initial generation of basic conditions near the electrode surface on consumption of protons by the palladium. The basic conditions favour the precipitation of aluminium (oxy)-hydroxide (with adsorbed sulfate balancing the charge), which bonds to the surface of the electrode, resulting in a rapid increase in the mass. The mass of hydrogen absorbed by the palladium was found to be insignificant compared to the mass of precipitate deposited. When the reaction rate of base formation is slowed with reversal of potential, there is still sufficient precipitate near the electrode to allow continuation of mass deposition. Once the base formation is stopped, material still diffuses to and adds to the electrode surface. Once $0 \mathrm{~V}$ is reached then the deposit is slowly removed from the electrode surface, presumably dissolving back into solution.

Calcination of cathodically-induced aluminium (oxy)-hydroxide precipitates was studied using temperature-ramped XRD measurements. As noted above, at room temperature, XRD patterns were characteristic of an amorphous material, indicating that film deposition is disordered, small particles of aluminium (oxy)-hydroxide 
forming and coagulating with no long range order. XRD patterns were then recorded at a series of temperatures up to $1150^{\circ} \mathrm{C}$ (Fig. 4) for samples mounted on a silicon (100) wafer. When performing the initial temperature ramp experiments, the presence of residual aluminium sulfate was observed in a weakly crystalline form. Upon heating, no reflections of significant intensity are observed until $900^{\circ} \mathrm{C}$, when a pattern matching $\gamma-\mathrm{Al}_{2} \mathrm{O}_{3}$ is observed, with a diffuse reflection occurring at $46.2^{\circ}$, which persists until the temperature is increased above $1100^{\circ} \mathrm{C}$. If the sample was returned to room temperature once the $\gamma-\mathrm{Al}_{2} \mathrm{O}_{3}$ had formed and before $1100^{\circ} \mathrm{C}$, then the $\gamma-\mathrm{Al}_{2} \mathrm{O}_{3}$ form was stable. At $1150^{\circ} \mathrm{C}$ sharp reflections matched to $\alpha-\mathrm{Al}_{2} \mathrm{O}_{3}$ (which occurs as the mineral corundum in Nature) are observed, the reflections associated with $\gamma-\mathrm{Al}_{2} \mathrm{O}_{3}$ disappearing. Upon cooling, the $\alpha-\mathrm{Al}_{2} \mathrm{O}_{3}$ is indefinitely metastable at $200^{\circ} \mathrm{C}$ (Fig. 4).

3.2 Electrical parameter response of aluminium (oxy)-hydroxide films with variation of relative humidity

For the investigation of electrical parameter response to variation of relative humidity, aluminium (oxy)-hydroxide films were prepared as bridging precipitates across twin palladium working electrodes. In earlier studies [13] we have shown that impedance varies linearly with relative humidity in each of the ranges 6 - 40 and $40-$ 90\%. Following considerable time spent on material deposition fundamentals, such as electrode configuration and design, the aluminium (oxy)-hydroxide film relative humidity response was now characterised in further depth, to include a range of electrical parameters. A greater number (up to 12) of relative humidities, film electrochemical deposition techniques and humidity response parameters were studied, and sensor responses were compared to those of a range of commercial sensors. 
With the newly established electrode preparation regime, described above, successful bridging of precipitate across two palladium electrodes in a twin configuration from a $0.01 \mathrm{~mol} \mathrm{dm} \mathrm{dm}^{-3}$ aqueous aluminium sulfate solution was reproducibly established using a galvanostatic current density of $-20 \mathrm{~mA} \mathrm{~cm}{ }^{-2}$ for 45 min, or a potential of $-3.2 \mathrm{~V}$ vs. $\mathrm{Ag} \mid \mathrm{AgCl}\left(3 \mathrm{~mol} \mathrm{dm}{ }^{-3} \mathrm{NaCl}\right)$ for $45 \mathrm{~min}$, or on potential stepping between -3.2 and $0.5 \mathrm{~V}$ at 20,30 or $40 \mathrm{~s}$ intervals for $1 \mathrm{~h}$. Once formed, the adhered precipitate was dried in air at room temperature, and the twin electrode then mounted in a constant humidity chamber, allowed to equilibrate, and then an ac signal applied between the two electrodes. A full range of temperaturecontrolled humidity chambers, with saturated salt solutions, were used.

To test the aluminium (oxy)-hydroxide-based sensors for the optimal applied electrical signal and measurement parameters, 3-D plots of linearity (over the range 6 - 85\% relative humidity) of response were plotted against applied ac signal amplitude and frequency. Linearity was imposed as a desirable characteristic, although it is possible that a more complex response, for example polynomial, may produce a more accurate fit for response to relative humidity at different applied ac signal amplitudes and frequencies. Linearity was chosen as a desirable characteristic because of the ease of integration into electronic circuitry.

For impedance, the optimal linear response was an applied ac signal amplitude of $100 \mathrm{mV}$ and a frequency of $1 \mathrm{kHz}$. The square of Pearson's correlation coefficient was used to assess linearity, and here was found to be 0.91 . The applied ac signal amplitude is lower than that used for commercially available metal oxide and polymer-based humidity sensors, which use values typically of $1 \mathrm{~V}$ ac. The variation with applied ac signal was small and this is demonstrated by the nature of the wave shape of the 3-D graph (Fig. 5). High and low frequencies showed a poor linear 
correlation with relative humidity, with typical values of the square of Pearson's correlation coefficient of approximately 0.65 .

The 3-D plot (Fig. 6) for resistance showed a much greater range of responses dependent on the applied ac signal amplitude and frequency. Optimal conditions were applied ac signal amplitudes greater than $100 \mathrm{mV}$ and very high frequencies. An applied ac signal amplitude of $1 \mathrm{~V}$ and frequency of $40 \mathrm{kHz}$ gave a square of Pearson's correlation coefficient value of 0.94. The resistance correlation was the highest of all the electrical parameters considered. Low applied ac signals gave consistent but weak correlations, with a square of Pearson's correlation coefficient of approximately 0.8. At higher applied ac signal amplitudes and low frequencies only a very poor correlation was observed, with a square of Pearson's correlation coefficient of approximately 0.3 .

For inductance (Fig. 7), optimal conditions for measurement of relative humidity were an applied ac signal amplitude of $20 \mathrm{mV}$ and a frequency of $150 \mathrm{~Hz}$, the value of the square of Pearson's correlation coefficient under these conditions being 0.92 . The $20 \mathrm{mV}$ signal is an advantage, as smaller ac signals are typically easier to generate especially at higher frequencies. High frequencies showed no correlation with a linear response to relative humidity. The same wave shape is observed for inductance (Fig. 7) as impedance (Fig. 5), with little variation in response when the ac signal is varied.

Capacitance showed the poorest response to relative humidity of all the electrical parameters tested. A plateau region (Fig. 8) with a typical square of Pearson's correlation coefficient of approximately 0.77 was observed for all ac signals up to a frequency of $1.5 \mathrm{kHz}$. At frequencies greater than this the linear response is worse. 
From these results, measurement of impedance or resistance allowed a linear response of the aluminium (oxy)-hydroxide film to relative humidity to be correlated with correct choice of applied ac signal amplitude and frequency. For example, Fig. 9 shows the best result in terms of linearity of impedance response to relative humidity for an individually calibrated film that was tested using an applied ac signal amplitude of $100 \mathrm{mV}$ at a frequency of $1 \mathrm{kHz}$. A square of Pearson's product moment correlation coefficient of 0.9621 , applicable between 11 and $85 \%$ relative humidity, is highly competitive with the commercial sensors tested here. The response of the film gave a relative humidity accurate to $\pm 10 \%$ across the range tested. The error bars indicated on the graph (Fig. 9) show two standard deviations from the mean, at the 95.5\% confidence interval. The film tested (Fig. 9) had an average electrical impedance response of $-28 \mathrm{k} \Omega$ per $1 \%$ relative humidity. The impedance response time ( $\mathrm{t}_{90 \%}$ ) of the film to a step change in relative humidity ( 33 to $85 \%$ at $25^{\circ} \mathrm{C}$ ) was $40 \pm 10 \mathrm{~s}$, as similar to commercial sensors. However, the most precise readings were obtained when the aluminium (oxy)-hydroxide films were exposed for at least 20 min. Film response was most stable once exposed to a particular relative humidity, with impedance readings remaining constant for at least $48 \mathrm{~h}$. This characteristic could be useful in a warning system, when a change in relative humidity could damage an industrial process. Any change in relative humidity would be registered as a change in impedance and an appropriate alarm could be raised. Stable readings were not observed when films were exposed to relative humidities above $85 \%$, with a constant slow decrease in impedance observed. The readings drifted, resulting in an apparent increase in the relative humidity, although this did not impair the response of the film. This is a well-known effect for metal oxide films exposed to high humidities [14]. When films were exposed to lower relative humidities, stable readings were once 
again observed. For a galvaostatically prepared film the linear response and standard deviation were measured (Fig. 9). The square of Pearson's product moment correlation was 0.9621 and the line of best fit had an equation of $\mathrm{y}=-0.0277 \mathrm{x}+$ 14.683. For galvanostatically-prepared films, the linearity of response down to low relative humidity values was in contrast to the poor sensitivity in this region that was found for films prepared by potential cycling, both in previous studies [13] and reproduced here. In previous studies, the gradient difference between the response at low and high humidity was attributed to different conduction mechanisms [13]. At low humidity, a phonon-induced electron tunnelling conduction mechanism was proposed. At high humidity, defined once mono-layer water coverage had been attained, proton conduction dominated.

The response of the films characterised here was compared to the performance of four commercial sensors. The manufacturers' recommended amplitude and frequency values were used. Two of the sensors had a better linearity of response than the aluminium (oxy)-hydroxide-based sensor. A metal oxide humidity sensor, with the active element of $\mathrm{NiO}$, had a linear impedance response (with values between $1.1 \mathrm{k} \Omega$ and $49 \mathrm{M} \Omega$ ) over the range 6 - 97\% relative humidity, with a square of Pearson's product moment correlation coefficient of 0.98 . Likewise, a humidity sensor, with a polymer film active element, showed an excellent response to relative humidity. In this case, a power trend line for the impedance response (with values from $1-1000$ $\Omega$ ) was fitted and showed an almost perfect fit, with a square of Pearson's product moment correlation value of 0.99 . The range of relative humidities covered was from 29 to 85\%. The aluminium (oxy)-hydroxide sensor had a better linear response than two of the commercial sensors tested. A capacitive type humidity sensor with a polymer film active element generated a capacitance change over the narrow range of 
145 - 175 pF for 11 - 85\% relative humidity. The capacitance values were widely spread, and this was reflected in the square of Pearson's product moment correlation, which had a value of 0.87 . The final humidity sensor was likewise a capacitive type humidity sensor, with a polymer film active element, and also showed a variance in its response to relative humidity. A capacitance change over the narrow range of 250 290 pF between 11 - 75\% relative humidity was observed. The square of Pearson's product moment correlation was 0.89 .

\subsection{Mechanism of the cathodically-induced precipitation}

To follow are possible reactions occurring under sufficiently negative applied potential at the palladium electrode surface.

$$
\begin{aligned}
& \mathrm{H}^{+}+\mathrm{e}^{-} \rightarrow \mathrm{H}_{\mathrm{ads}} \\
& \mathrm{H}_{2} \mathrm{O}+\mathrm{e}^{-} \rightarrow \mathrm{H}_{\mathrm{ads}}+\mathrm{OH}^{-} \\
& \mathrm{Pd}+\mathrm{H}_{\mathrm{ads}} \rightarrow \mathrm{PdH}_{\mathrm{ads}} \\
& 2 \mathrm{H}^{+}+2 \mathrm{e}^{-} \rightarrow \mathrm{H}_{2} \\
& \mathrm{O}_{2}+2 \mathrm{H}_{2} \mathrm{O}+4 \mathrm{e}^{-} \rightarrow 4 \mathrm{OH}^{-}
\end{aligned}
$$

The initial $\mathrm{pH}$ of the $0.01 \mathrm{~mol} \mathrm{dm}^{-3}$ aluminium (III) sulfate solution is approximately 4, so reaction (1) will first occur as the main reduction reaction at the electrode. As the concentration of protons decreases and the $\mathrm{pH}$ rises, the main electrode reaction will then be the reduction of water in order to sustain the current, reaction (2). Palladium will then absorb any adsorbed hydrogen on the electrode surface, reaction (3). Unlike with platinum as the cathode, for palladium, no hydrogen gassing is observed and therefore reaction (4) is unimportant, until hydrogen saturation occurs at 
long electrolysis times. Solutions purged with argon to remove dissolved oxygen produced aluminium (oxy)-hydroxide films identical to those of unpurged solutions, so reaction (5) is likewise unimportant.

In the initial solution, the aluminium species will be in the form of the hydrated $\mathrm{Al}^{3+}$ cation. Once the $\mathrm{pH}$ has started rising at the palladium/electrolyte solution interface, the 'cathodically-induced' precipitation reaction will begin, following reactions (6) to (9).

$\mathrm{Al}^{3+}+\mathrm{OH}^{-} \rightleftharpoons \mathrm{Al}(\mathrm{OH})^{2+}$

$\mathrm{Al}(\mathrm{OH})^{2+}+\mathrm{OH}^{-} \rightleftharpoons \mathrm{Al}(\mathrm{OH})_{2}^{+}$

$\mathrm{Al}(\mathrm{OH})_{2}^{+}+\mathrm{OH}^{-} \rightleftharpoons \mathrm{Al}(\mathrm{OH})_{3}$

$\mathrm{Al}(\mathrm{OH})_{3}+\mathrm{OH}^{-} \rightleftharpoons \mathrm{Al}(\mathrm{OH})_{4}^{-}$

The speciation of aluminium under high $\mathrm{pH}$ conditions is complex and the material that forms following coagulation of particles is best described as aluminium '(oxy)hydroxide', which will also contain occluded water, and as has been shown here, sulfate from solution. The source of the sulfate will be surface adsorption on the forming precipitate as reported for hydrolysis-precipitation studies [15] and/or residue solution left on the precipitate which, when the solvent evaporates, leaves behind aluminium sulfate.

\section{Conclusions}


Aluminium (oxy)-hydroxide films, with humidity sensing electrical properties, are conveniently prepared by electrolysis of aqueous aluminium sulfate solutions using hydrogen-sorbing cathodes. Optimal experimental conditions for precipitate formation require a clean palladium electrode and a constant current across the working electrode/electrolyte solution interface. The term 'cathodically-induced precipitation' best describes the film formation process. As the process is not a direct electrochemical reaction, the terms cathodic precipitation or electroprecipitation could be misleading. Galvanostatically-prepared aluminium (oxy)-hydroxide films exhibited a linear impedance response to relative humidity at an applied ac signal of $100 \mathrm{mV}$ at $1 \mathrm{kHz}$. The aluminium (oxy)-hydroxide films are ceramic oxide precursors, since heating has been shown by XRD to form both $\gamma-\mathrm{Al}_{2} \mathrm{O}_{3}$ and $\alpha-\mathrm{Al}_{2} \mathrm{O}_{3}$. Humidity testing of such alumina materials prepared by this route is planned, using composites fabricated with suitable polymeric binders.

\section{Acknowledgements}

We thank the EPSRC (GR/S34434/01) for financial support, Dr Andrew Wallace, for background advice, and Dr Sandra E Dann for assistance with the XRD measurements and interpretation. 


\section{References}

[1] G.H.A. Therese, P.V. Kamath, Electrochemical synthesis of metal oxides and hydroxides, Chem. Mater. 12 (2000) 1195-1204.

[2] P.J. Mitchell, G.D. Wilcox, An electrochemical route to pre-shaped ceramic bodies, Nature (London) 357 (1992) 395-397.

[3] R.N. Bhattacharya, R. Noufi, L.L. Roybal, R.K. Ahrenkiel, YBaCuO superconductor thin films via an electrodeposition process, J. Electrochem. Soc. 138 (1991) 1643-1645.

[4] P. Slezak, A. Wiechowski, Aqueous electrochemical synthesis of $\mathrm{YBa}_{2} \mathrm{Cu}_{3} \mathrm{O}_{7-\mathrm{x}}$ superconductors, J. Electrochem. Soc. 138 (1991) 1038-1040.

[5] R. Janes, P.M.S. Monk, R.D. Partridge, S. B. Hall, Electrodeposition of thinfilm rare-earth oxocuprates, J. Mater. Chem. 6 (1996) 183-186.

[6] P.M.S. Monk, R. Janes, R.D. Partridge, Electrochemical deposition of the hydroxide precursors to $\mathrm{YBa}_{2} \mathrm{Cu}_{3} \mathrm{O}_{7-\delta}$ and related phases, J. Mater. Chem. 8 (1998) 1779-1781.

[7] P.M.S. Monk, S.L. Chester, D.S. Higham, R.D. Partridge, Electrodeposition of cobalt oxide doped with additional metal oxides, Electrochim. Acta 39 (1994) 2277-2284.

[8] P.M.S. Monk, R.D. Partridge, R. Janes, M.J. Parker, Electrochromic tungsten oxide: doping with two or three other metal oxides, J. Mater. Chem. 4 (1994) 1071-1074.

[9] P.M.S. Monk, T. Ali, R.D. Partridge, The effect of doping electrochromic molybdenum oxide with other metal oxides: correlation of optical and kinetic properties, Solid State Ionics 80 (1995) 75-85. 
[10] P.M.S. Monk, S. Ayub, Solid-state properties of thin film electrochromic cobalt-nickel oxide, Solid State Ionics 99 (1997) 115-124.

[11] P.M.S. Monk, S.P. Akhtar, J. Boutevin, J.R. Duffield, Toward the tailoring of electrochromic bands of metal-oxide mixtures, Electrochim. Acta 46 (2001) 2091-2096.

[12] P.J. Mitchell, R.J. Mortimer, A. Wallace, An in situ optical micrographic study of metal hydroxide film growth during potential controlled cathodic precipitation, 188th Electrochemical Society Meeting, 95-2, The Electrochemical Society, Chicago, Illinois, 1995, pp. 616-617.

[13] P.J. Mitchell, R.J. Mortimer, A. Wallace, Evaluation of a cathodically precipitated aluminium hydroxide film at a hydrogen-sorbing palladium electrode as a humidity sensor, J. Chem. Soc., Faraday Trans. 94 (1998) 24232428.

[14] E. Traversa, Ceramic sensors for humidity detection: the state-of-the-art and future developments, Sens. Actuators B Chem. 23 (1995) 135-156.

[15] F. Ansbacher, A.C. Jason, Effects of water vapour on the electrical properties of anodized alumina, Nature (London) 171 (1953) 177-178.

[16] H. de Hek, R.J. Stol, P.L. de Bruyn, Hydrolysis-precipitation studies of aluminium(III) solutions, J. Colloid Interface Sci. 64 (1978) 72-89. 


\section{Biographies}

Roger Mortimer (CChem, FRSC) is a Professor of Physical Chemistry at Loughborough University. His BSc degree in Chemistry (1977) is from Imperial College London, where he remained to carry out $\mathrm{PhD}$ research (1977/80) in catalysis. As a postdoctoral research fellow (1980/81) and visiting associate in chemistry (1988), at California Institute of Technology, he initiated his electrochemical research interests, which were further developed at the University of Exeter where he was Demonstrator in Physical Chemistry (1981/83) and then an SERC postdoctoral research fellow (1983/84). Lecturing positions in physical chemistry at Anglia Ruskin University (1984/87) and analytical chemistry at Sheffield Hallam University (1987/89) ensued, followed by his appointment (1989) as a Lecturer B in Physical Chemistry at Loughborough University. He was promoted to senior lecturer in 1999, to reader in 2001, and to a personal chair in 2006. His current research interests concern the preparation and study of established and novel organic, polymeric and inorganic materials on electrode surfaces, with applications in sensors, electro-optive displays and energy conversion devices.

Russell Mayes received a BSc degree in Chemistry and Sports Science from Loughborough University in 2003. During 2003-2006 he undertook a successful PhD programme at Loughborough University, where he investigated the fundamentals and applications of ceramic precursor films prepared by cathodically-induced precipitation. 
Table 1 Compounds used for saturated salt solutions and the relative humidity to 2 significant figures held above them.

\begin{tabular}{ccc}
\hline Compound & Relative humidity & Supplier (purity) \\
\hline Lithium bromide dihydrate & $6 \%$ & Aldrich ( $>98 \%)$ \\
Lithium chloride monohydrate & $11 \%$ & Aldrich ( $>99 \%)$ \\
Calcium chloride dihydrate & $29 \%$ & Fisher (analytical) \\
Magnesium chloride hexahydrate & $33 \%$ & Aldrich (>99\%) \\
Potassium carbonate & $43 \%$ & Aldrich ( $>99 \%)$ \\
Calcium nitrate & $51 \%$ & Fisher (analytical) \\
Sodium nitrate & $65 \%$ & Fisher ( $>99.5 \%)$ \\
Potassium iodide & $69 \%$ & Aldrich $(>99 \%)$ \\
Sodium chloride & $75 \%$ & Fisher ( $>99.5 \%)$ \\
Potassium bromide & $81 \%$ & Aldrich $(>99 \%)$ \\
Potassium chloride & $85 \%$ & Aldrich $(>99 \%)$ \\
Potassium sulfate & $97 \%$ & Aldrich (99\%) \\
\hline
\end{tabular}




\section{Figure captions}

Fig. 1

SEM of aluminium (oxy)-hydroxide prepared galvanostatically at $-20 \mathrm{~mA} \mathrm{~cm}^{-2}$. To obtain this picture an electron backscatter detector was used, with the sample under a variable pressure atmosphere of nitrogen.

Fig. 2

IR spectrum of the aluminium (oxy)-hydroxide deposit. The sample was prepared in a $\mathrm{KBr}$ disc and the scan limits were 400 to $4000 \mathrm{~cm}^{-1}$.

Fig. 3

Mass and electrode potential versus time for aluminium (oxy)-hydroxide film deposition on a palladium coated gold/quartz crystal.

Fig. 4

XRD patterns for cathodically-precipitated aluminium (oxy)-hydroxide material. Computer database searching showed the final product to be corundum, $\alpha-\mathrm{Al}_{2} \mathrm{O}_{3}$.

Fig. 5

Linearity of impedance response between $11 \%$ and $85 \%$ relative humidity. Linearity was measured using the square of Pearson's correlation coefficient $\left(\mathrm{R}^{2}\right)$.

Fig. 6

Linearity of resistance response between $11 \%$ and $85 \%$ relative humidity.

Fig. 7

Linearity of inductance response between $11 \%$ and $85 \%$ relative humidity.

Fig. 8

Linearity of capacitance response between $11 \%$ and $85 \%$ relative humidity.

Fig. 9 
Impedance response of an aluminium (oxy)-hydroxide film to changes in relative humidity. An applied ac signal amplitude of $100 \mathrm{mV}$ at $1 \mathrm{kHz}$ was applied. 
Fig. 1

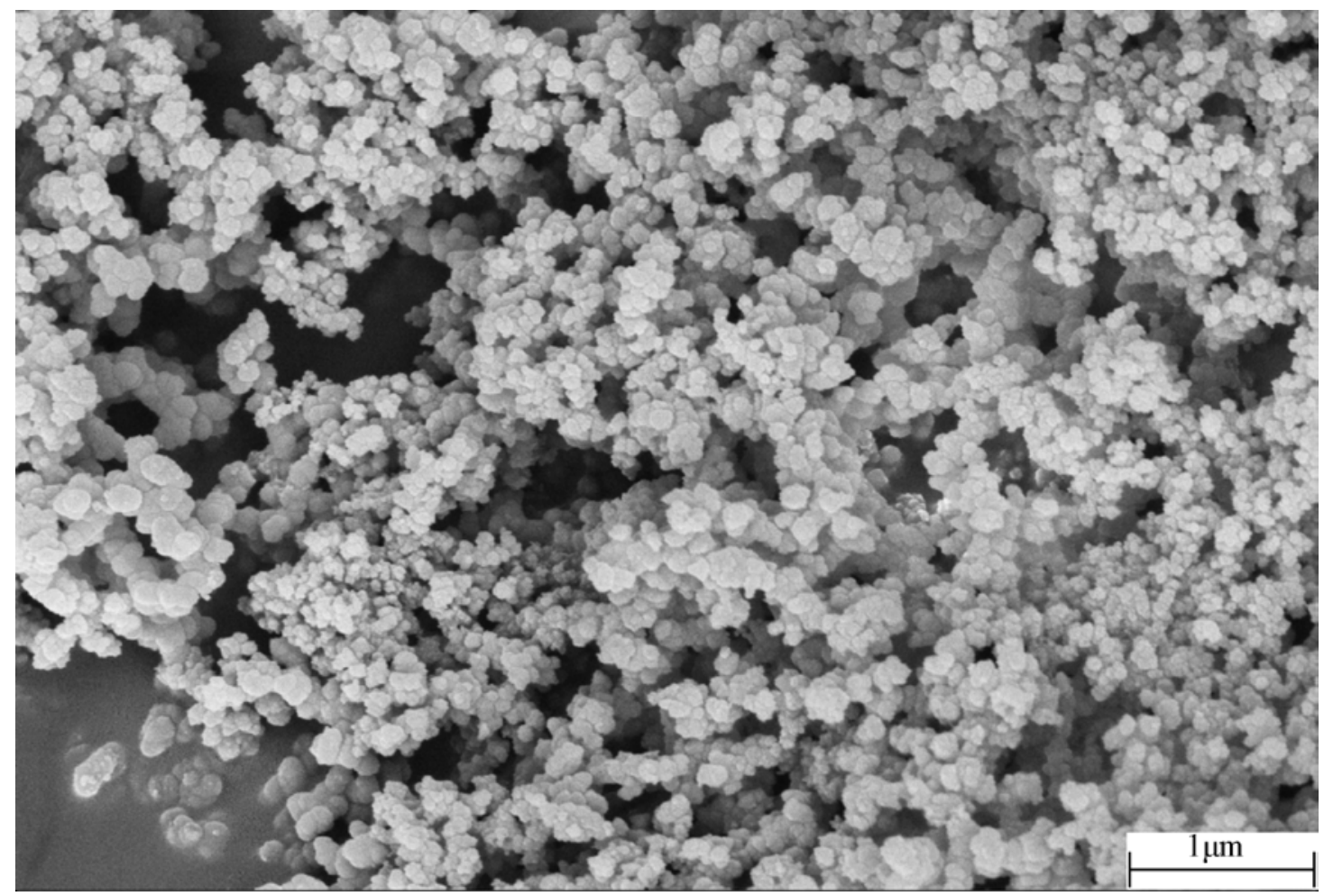


Fig. 2

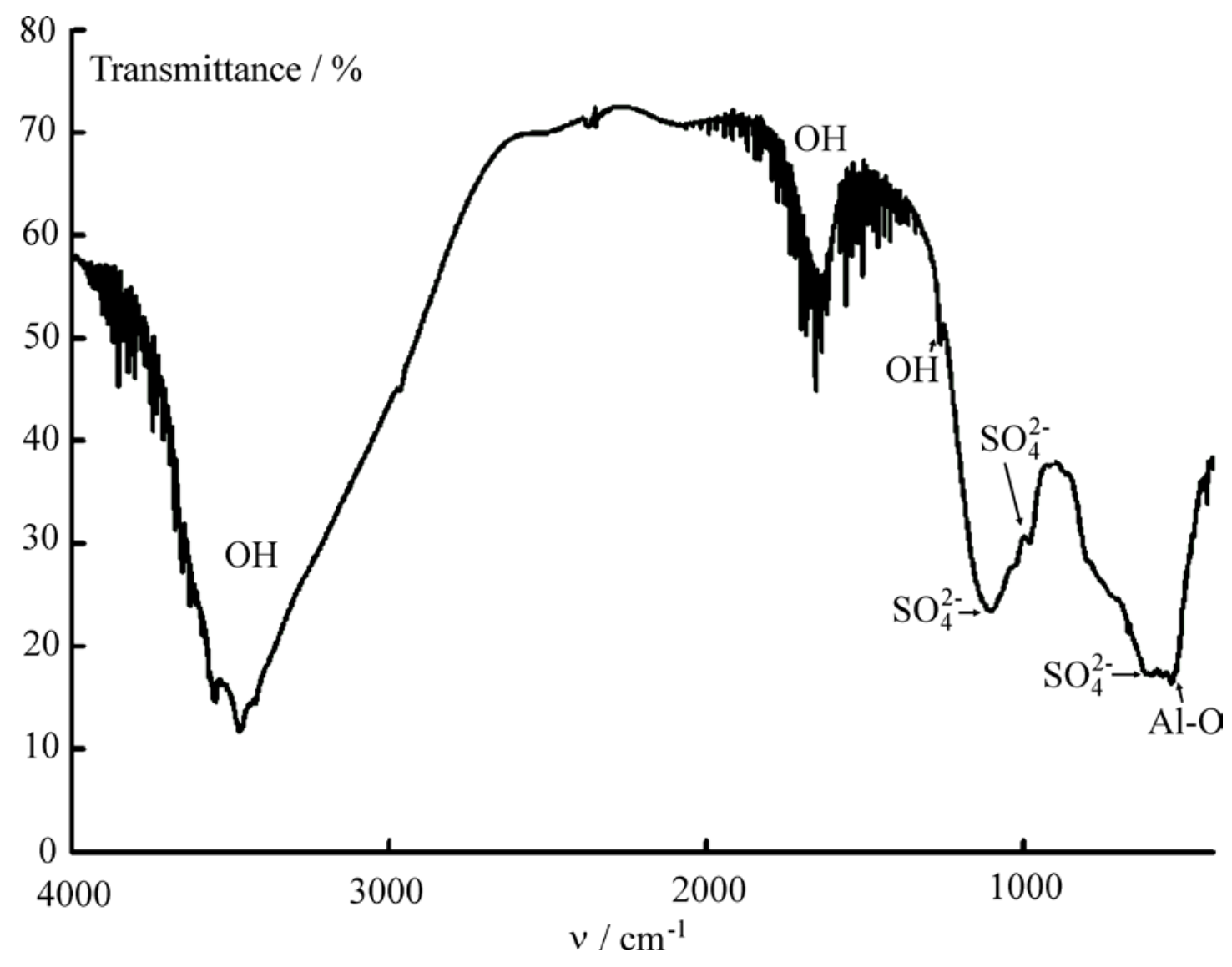


Fig. 3

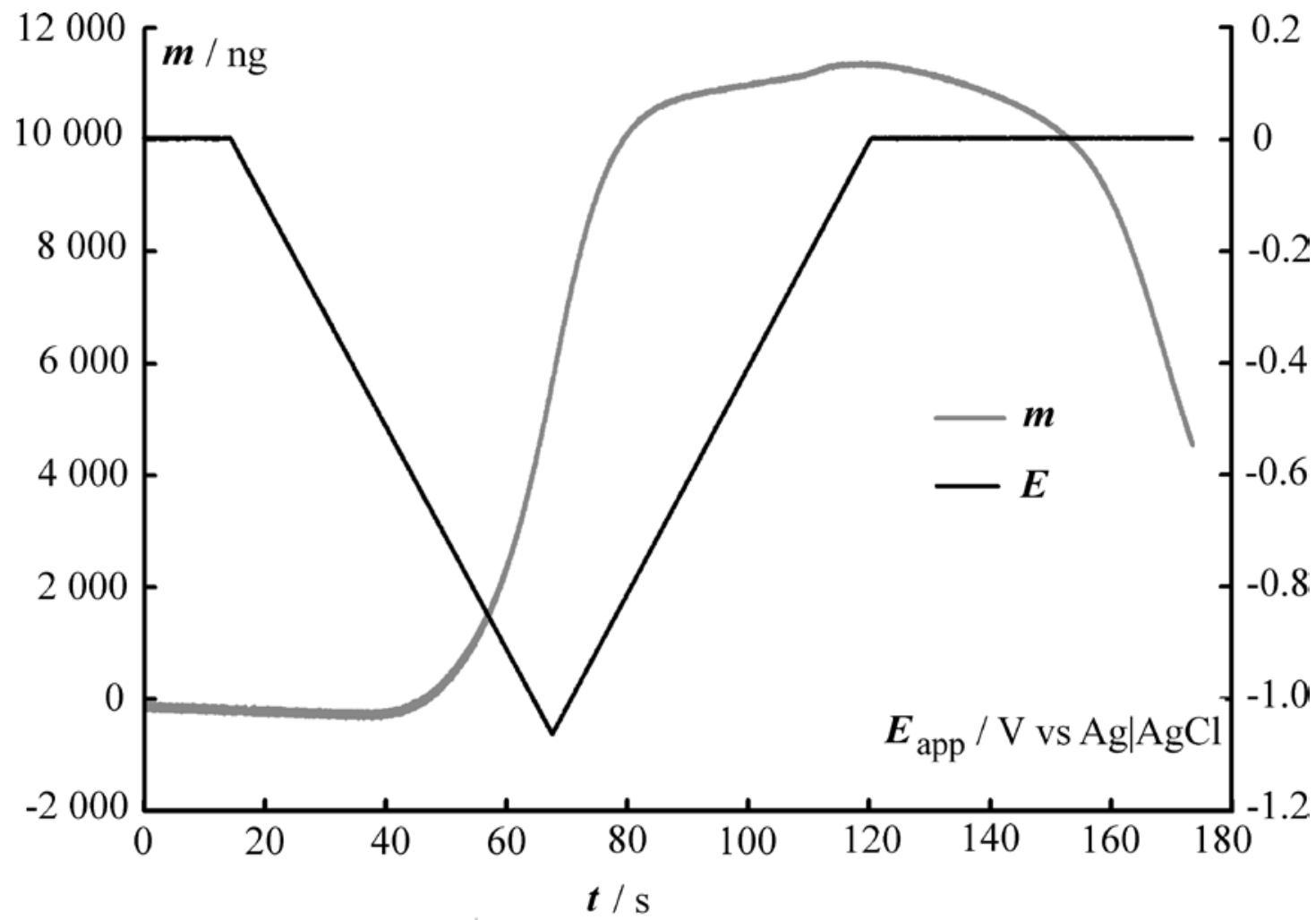


Fig. 4

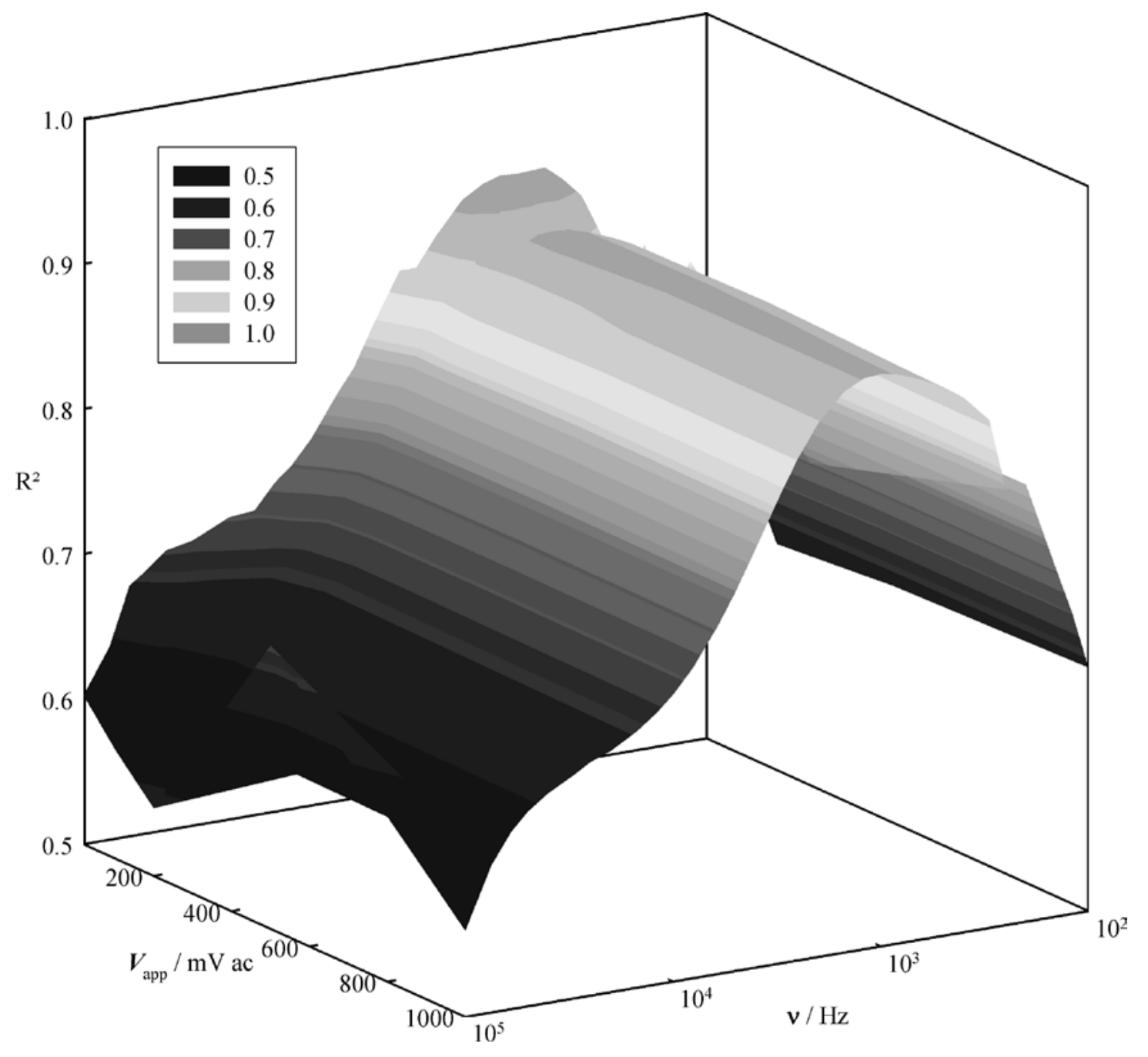


Fig. 6

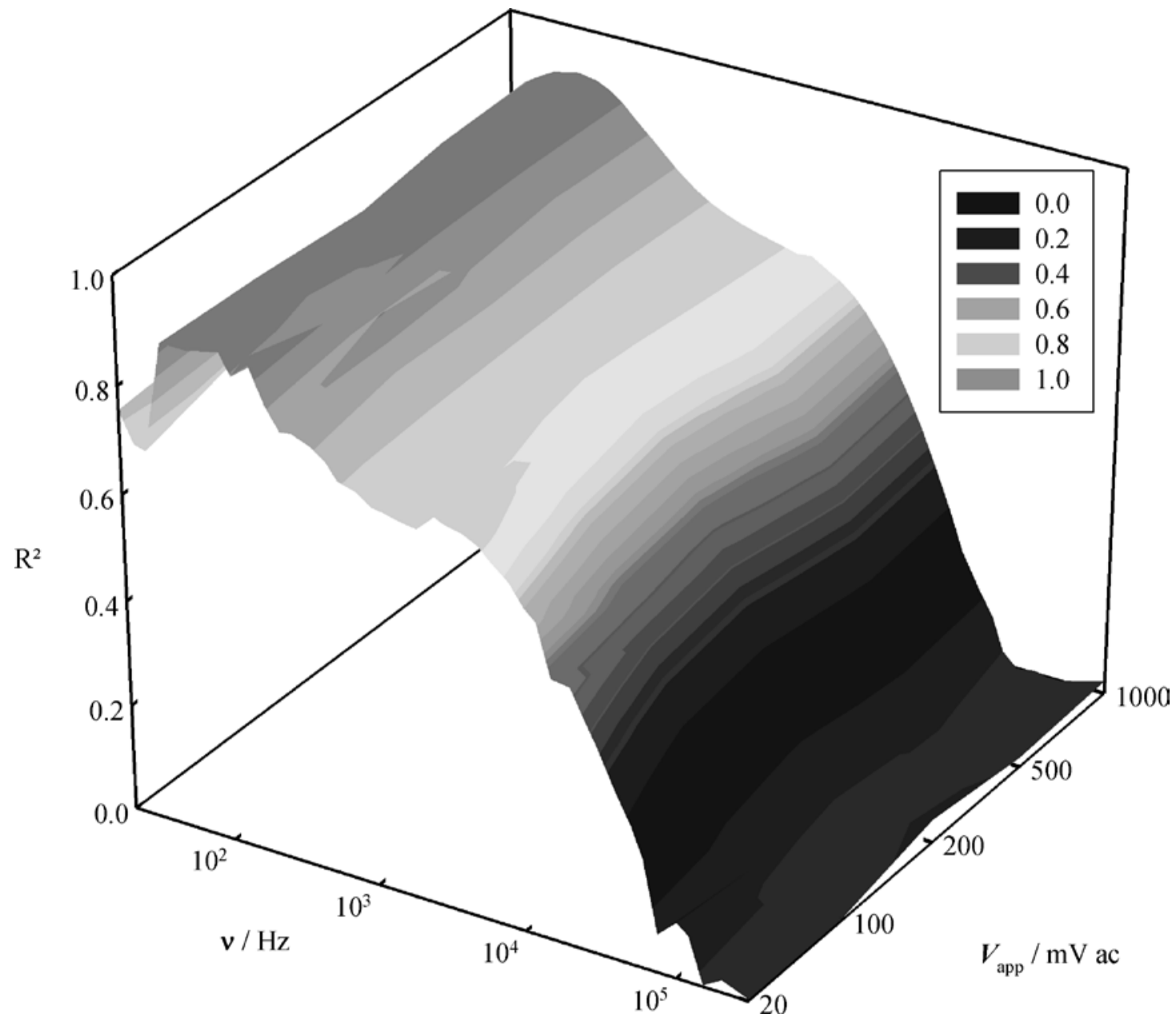


Fig. 7

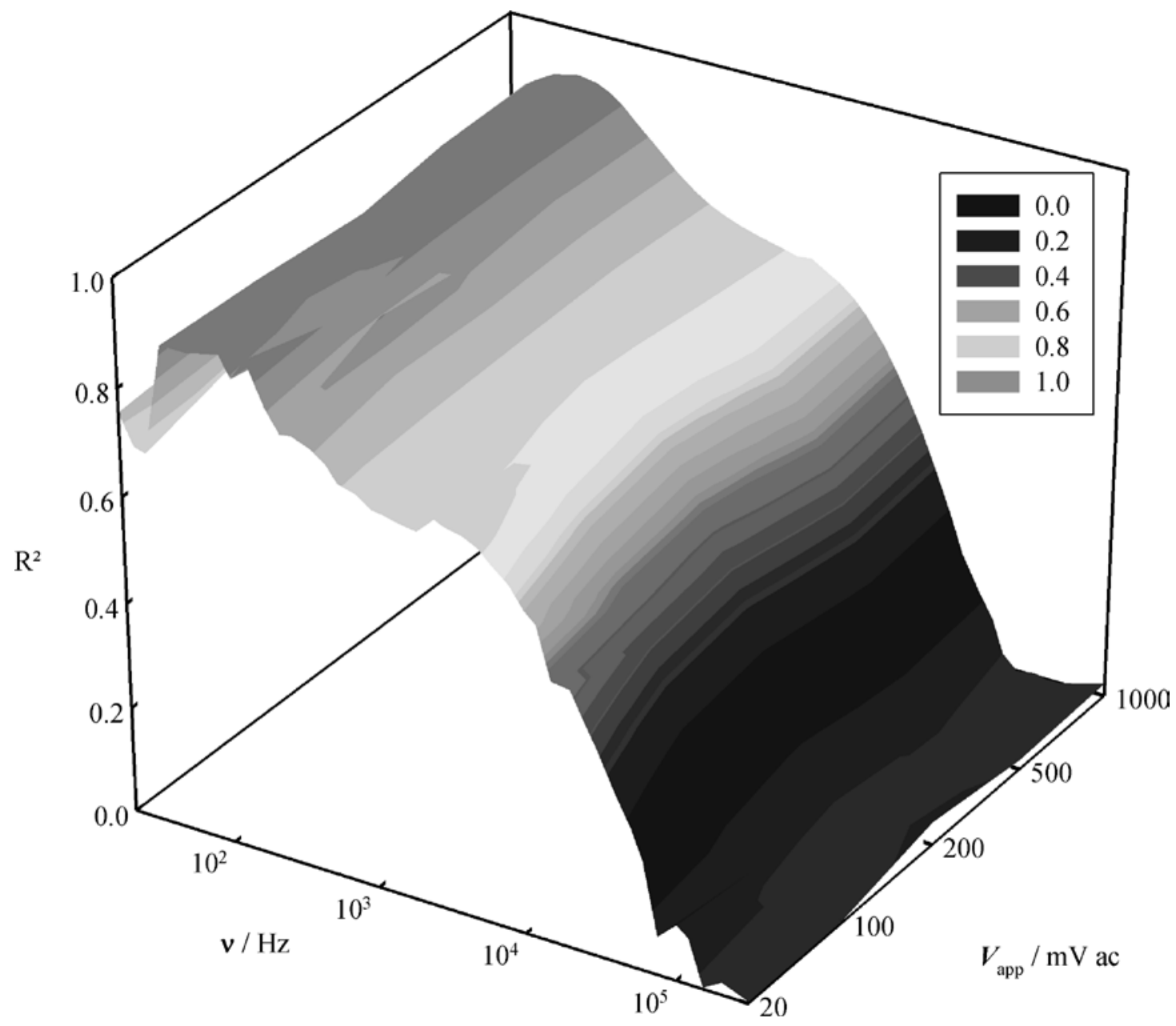


Fig. 8

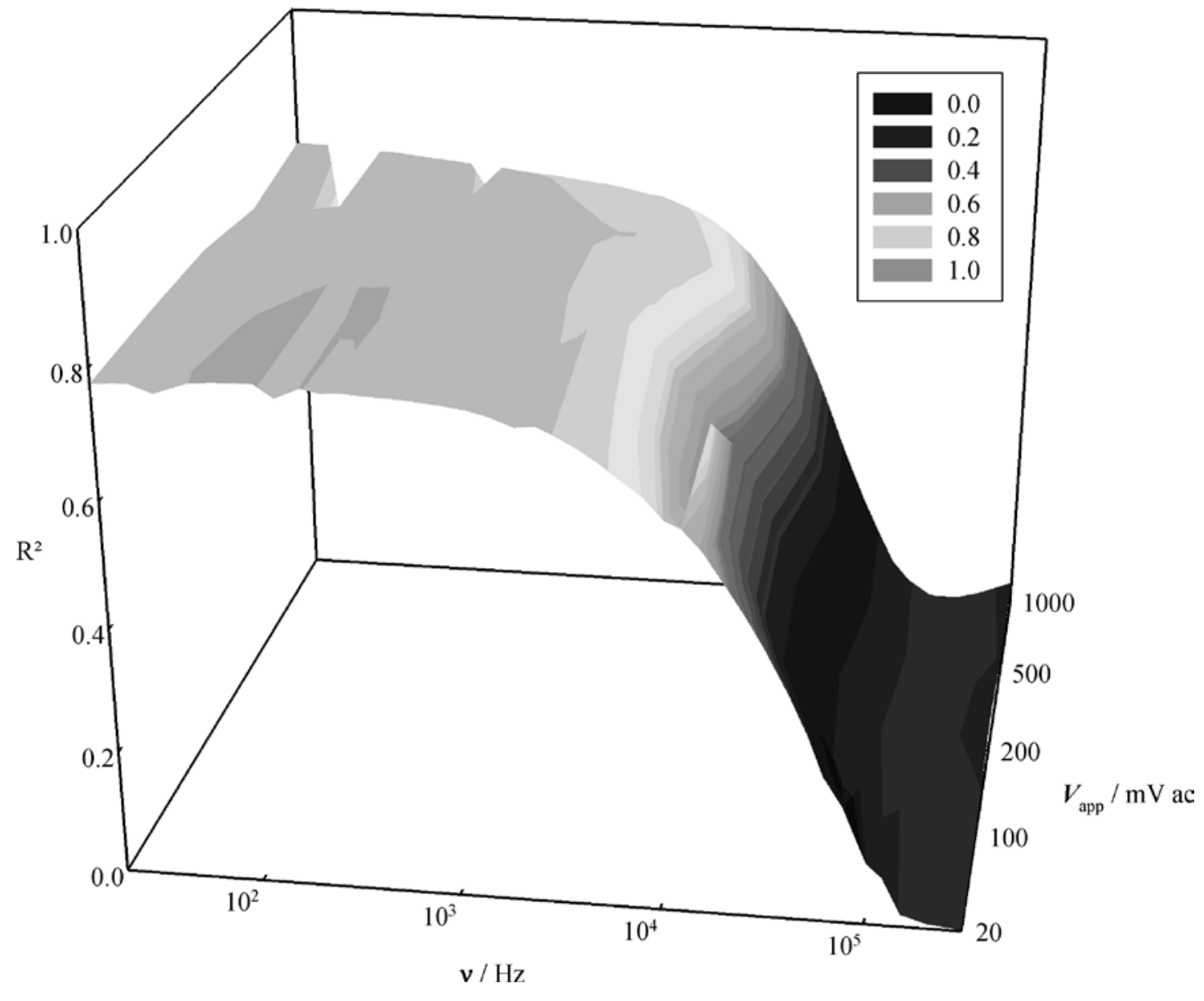


Fig. 9

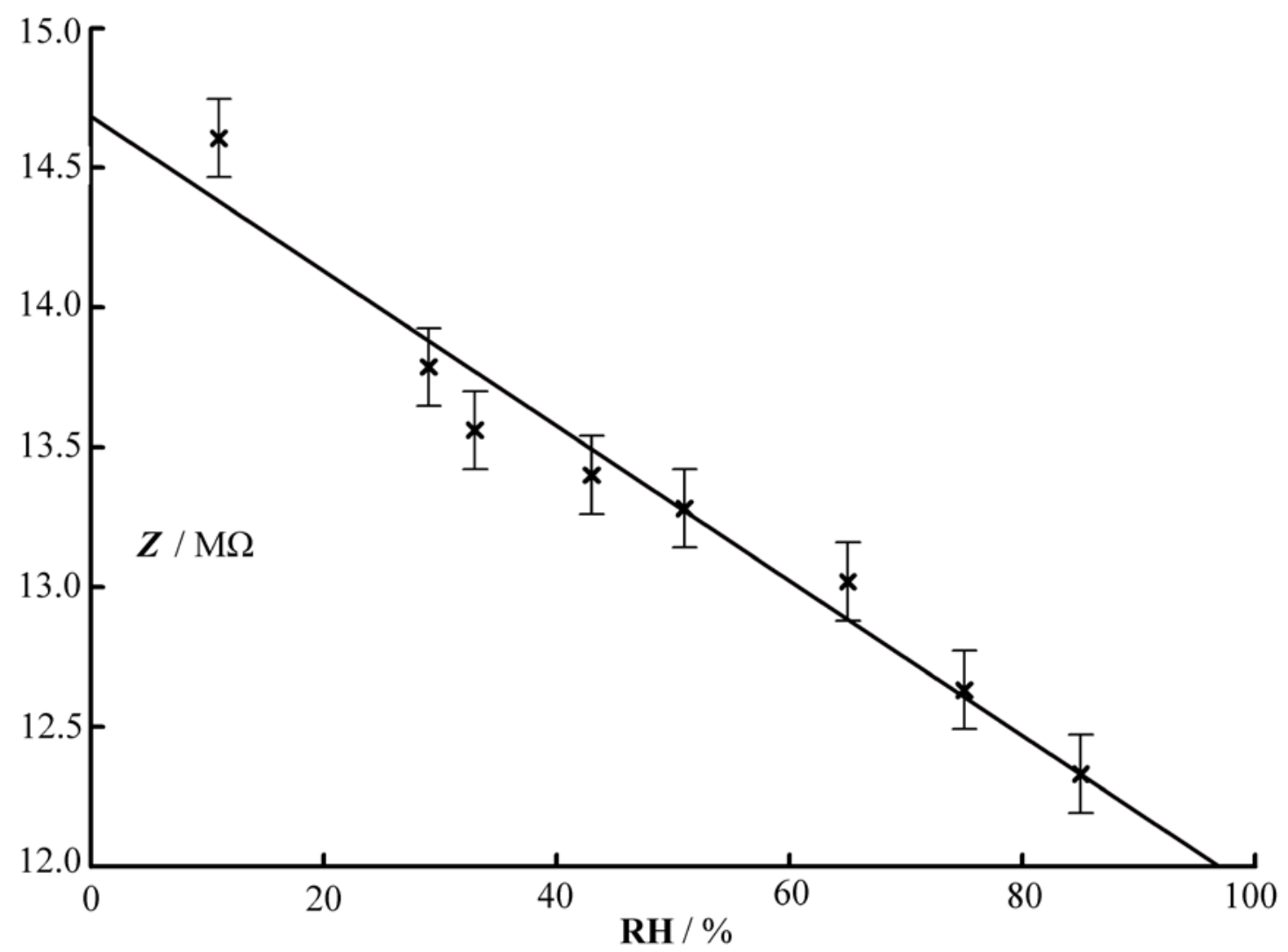

